\title{
Control of Weld Residual Stress in a Thin Steel Plate through Low Transformation Temperature Welding Consumables
}

\author{
A new LTTW consumable for welding of advanced high-strength \\ steels was developed for welding thin sheets
}

BY X. WU, Z. WANG, J. R. BUNN, L. KOLBUS, Z. FENG, Z. YU, AND S. LIU

\begin{abstract}
Low transformation temperature welding (LTTW) consumables are characterized by a low martensite start temperature and a large fraction of martensite forming in the weld. It can efficiently reduce the tensile residual stress because the volume expansion associated with the martensitic transformation compensates for the thermal contraction during cooling. In this work, a LTTW wire, designated as EH200B, was created for the arc welding of advanced high-strength steel thin plates. In comparison to conventional ER70S-3 wires, this LTTW wire generated an opposite distortion pattern. Neutron diffraction measurements along the center thickness of the welded plates showed the maximum residual stress along the longitudinal direction (LD) in the weld region, and the heat-affected zone (HAZ) immediately adjacent to the weld region was reduced from $\sim 330 \mathrm{MPa}$ to below $240 \mathrm{MPa}$ by using the LTTW wire. A finite element (FE) model was developed to predict the residual stress distributions of the plates welded under these two wires. The simulation results showed reasonable agreement with the volume-average neutron diffraction data. Compressive residual stress in the weld region using the LTTW wire was predicted by the FE method. Electron backscattered diffraction and x-ray diffraction measurements confirmed $\sim 90 \%$ martensite was present in the LTTW weld. The fatigue life of DP980 steel lap joint panels using EH200B wire nearly doubled that of ER70S-3 wire. This improvement was attributed to the high strength and low LD residual stress in the weld and HAZ immediately adjacent to the weld.
\end{abstract}

\section{KEYWORDS}

- Low Transformation Temperature Welding Consumables

- Gas Metal Arc Welding • Weld Residual Stress

- Neutron Diffraction • Numerical Simulation

\section{Introduction}

There have been evolving applications of advanced highstrength steels (AHSSs) in the automotive industry due to the increasing demand in higher levels of car safety and fuel efficiency. Fusion welding of AHSS, such as gas metal arc welding (GMAW), generally produces undermatching weldments due to the limited strengths of the commercially available welding consumables (Ref. 1). Moreover, the presence of tensile residual stresses in the softened heat-affected zone (HAZ) often leads to premature failure/accidental fatigue fracture (Ref. 2). For automotive applications, significant distortion could also occur during the welding of thin AHSS sheets and thus be problematic for auto body assembly (Refs. 3, 4).

Methods for relieving residual stresses in thin plate welds include postweld heat treatment and postweld cold rolling (Refs. 5-7). These methods, however, are generally costly, time consuming, and limited by component size and geometry. An attractive alternative approach is to use low transformation temperature welding (LTTW) consumables that can control the evolution of tensile residual stress and distortion during the welding process by phase transformation, resulting in a large fraction of martensite. The concept of LTTW consumables was first proposed by Jones and Alberry in 1977 (Ref. 8). The volume expansion associated with the austeniteto-martensitic transformation could compensate for the thermal contraction during cooling. A low transformation temperature is critical to ensure no further thermal contraction occurs in the martensitic phase as the weld region cools back down to room temperature, since martensite has an extremely large elastic modulus (Ref. 8). Jones and Alberry reported the residual stress in AISI 316 stainless steel welds was decreased significantly using a $9 \mathrm{CrMo}$ wire due to the austeniteto-martensite transformation during cooling (Ref. 8). Compressive residual stress is also achievable, as reported by Ohta et al. (Ref. 9), where a 10Cr-10Ni LTTW consumable was used for welding in a 20 -mm-thick 1024 steel plate.

There have been rising interests in the development of LTTW filler alloys for various applications in the past two decades (Refs. 9-16). In these reported studies, the LTTW consumables contained up to $15 \mathrm{wt}-\% \mathrm{Ni}$ and $15 \mathrm{wt}-\% \mathrm{Cr}$, leading to a martensite starting temperature, $\mathrm{Ms}$, at $200^{\circ} \mathrm{C}$ or below (Ref. 17). There were also other reported benefits associated with LTTW wires, including improved fatigue strength (Refs. 18, 19), reduced distortion (Ref. 20), and enhanced fracture toughness (Ref. 21) in steel weldments. 

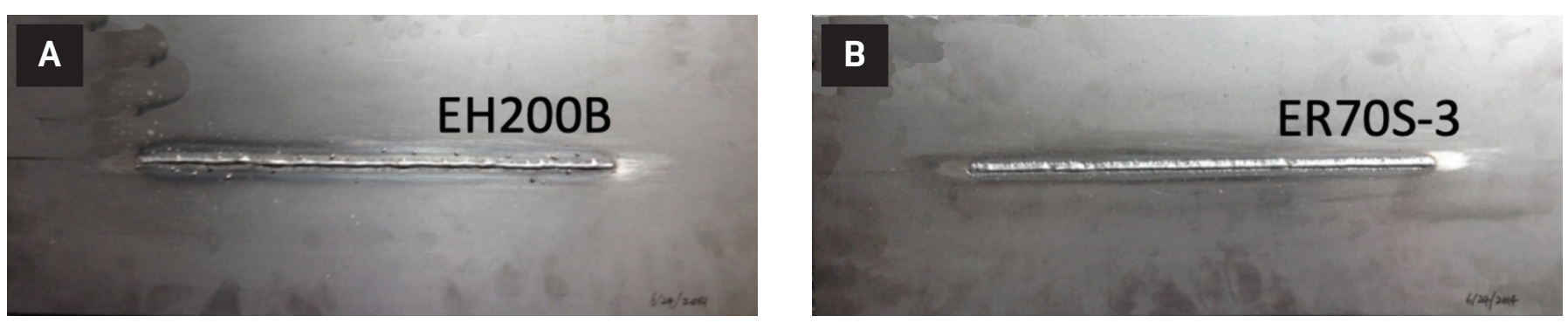

Fig. 1- Welded plates with a BOP weld with a length of $254 \mathrm{~mm}$ using (A) EH200B and (B) ER70S-3 wires.
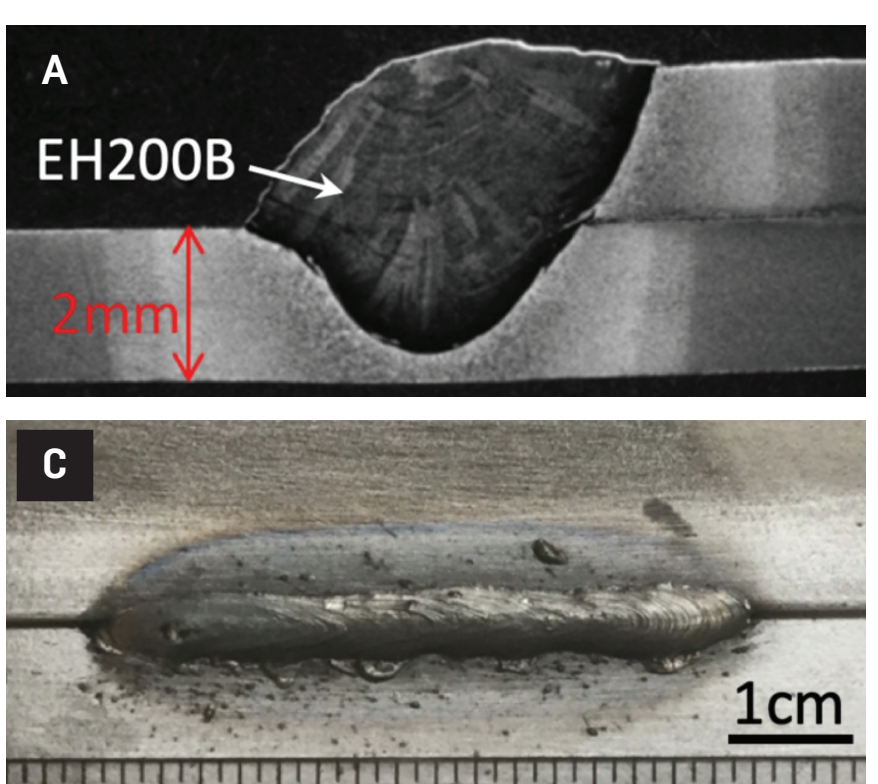
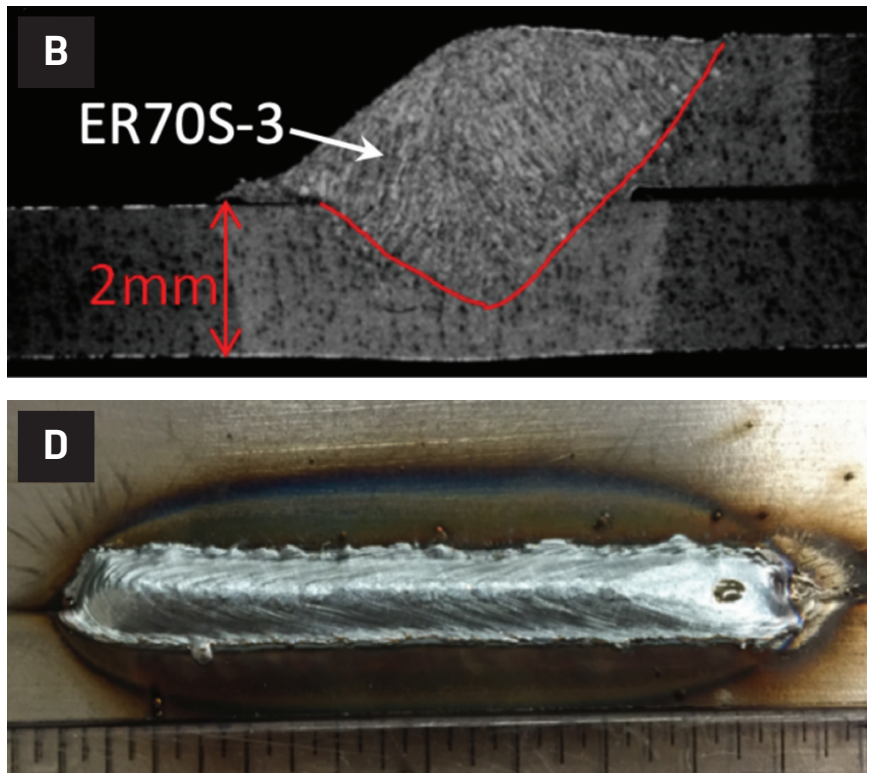

Fig. 2 - Optimized lap joint bead morphologies: A, B - Cross-sectional view of the lap joints using EH200B and ER70S-3 wires, respectively; C, D - top view of the lap joints using EH2OOB and ER70S-3 wires, respectively.

Presently, there is very limited research on LTTW consumables for welding of AHSS thin plates. Therefore, in this work, a new LTTW consumable was developed for welding thin sheets of AHSS DP980. Conventional ER70S-3 wire was also used to generate welds for comparison. The weldment microstructure was systematically examined using optical and electron microscopies, hardness mapping, and x-ray diffraction (XRD) methods. The residual stress profile was evaluated by neutron diffraction measurement and finite element modeling (FEM). The model coupled the thermal, mechanical, and metallurgical effects to provide the complete residual stress profile in the welded plates. A fatigue test was also performed in both weldments to compare their fatigue life.

\section{Experimental Details}

\section{LTTW Consumables}

In this study, a metal-cored LTTW consumable, namely EH200B, was fabricated based on an earlier design by earlier researchers of the Center for Welding, Joining and Coatings Research at Colorado School of Mines (Refs. 16, 22). The Eichelman and Hull equation (Ref. 23), as expressed below, was relied on to get the desired $\mathrm{Ms}$ temperature of $200^{\circ} \mathrm{C}$ :
$\mathrm{Ms}\left({ }^{\circ} \mathrm{C}\right)=1305-41.7 \mathrm{Cr}-61.1 \mathrm{Ni}-33.3 \mathrm{Mn}-27.8 \mathrm{Si}$ $-1667(C+N)$

where Ms is the martensite start temperature, and elemental weight percent is used in this calculation.

Table 1 tabulates the compositions and estimated Ms temperature of EH200B and commercial ER70S-3 wires that are commonly used for welding DP980 steel. The chromium and nickel equivalent $\left(\mathrm{Cr}_{\mathrm{eq}}\right.$ and $\left.\mathrm{Ni}_{\mathrm{eq}}\right)$ were calculated using the expressions below (in weight percent) (Ref. 24):

$$
C r_{e q}=C r+M o+1.5 S i+0.5 N b
$$

$$
N i_{e q}=N i+0.5 M n+30 C
$$

\section{Welding Procedure}

GMAW was used to make weldments with both wires. The wire diameter was 0.045 in. for both the solid ER70S-3 wire and the metal-cored EH200B wire. Two types of weldments were produced in this study, including bead-on-plate (BOP) welds for residual stress evaluation and lap joints for fatigue testing. The neutron diffraction method was used to 
Table 1 - Comparison of Wire Composition (wt-\%) and Calculated $M s\left({ }^{\circ} \mathrm{C}\right)$ Based on Eichelman and Hull Equation

\begin{tabular}{lccccccrrrrr} 
Wire & $\mathrm{C}$ & $\mathrm{Mn}$ & $\mathrm{Cr}$ & $\mathrm{Ni}$ & $\mathrm{Si}$ & $\mathrm{Mo}$ & $\mathrm{Ti}$ & $\mathrm{Cr}_{\text {eq }}$ & $\mathrm{Ni}_{\text {eq }}$ & $\left.\mathrm{Ms}^{\circ} \mathrm{C}\right)$ \\
\hline EH200B & 0.1 & 2.0 & 9.0 & 8.0 & 0.1 & 0.25 & 0.01 & 9.4 & 12.0 & 200 \\
ER70S-3 & 0.09 & 1.02 & 0.05 & 0.03 & 0.41 & $<0.01$ & $<0.01$ & 0.7 & 3.2 & 1106 \\
\hline
\end{tabular}

\begin{tabular}{|c|c|c|c|c|c|}
\hline ER70S-3 & 260 & 34.8 & 25 & 207 & 351 \\
\hline
\end{tabular}

*WFS (in./min) denotes wire feed speed in In. per min.

Table 3 - Optimized Welding Parameters for Lap Joints Using EH200B and ER70S-3 Wires

\begin{tabular}{cccccccc} 
Wire & $\begin{array}{c}\text { WFS } \\
\text { (in./min) }\end{array}$ & $\begin{array}{c}\text { Voltage } \\
\text { (V) }\end{array}$ & $\begin{array}{c}\text { Current } \\
\text { (A) }\end{array}$ & $\begin{array}{c}\text { Travel Speed } \\
\text { (in./min) }\end{array}$ & $\begin{array}{c}\text { Work Angle } \\
\text { (deg) }\end{array}$ & $\begin{array}{c}\text { Travel Angle } \\
\text { (deg) }\end{array}$ & $\begin{array}{c}\text { Heat Input } \\
\text { (J/mm) }\end{array}$ \\
\hline EH200B & 220 & 21.4 & 173 & 27 & 33 & 17 & 226.7 \\
ER70S-3 & 180 & 17.5 & 168 & 32 & 31 & 13 & 151.9 \\
\hline
\end{tabular}

measure and compare the residual stress distributions in BOP welds using LTTW and ER70S-3 wires, respectively. Note that the base material was A36 steel in BOP weldments to avoid complications associated with phase transformations in the DP980 base metal. A36 steel sheets with a dimension of $508 \times 203 \times 2 \mathrm{~mm}^{3}$ were used for BOP welds. For lap joints, 2-mm-thick DP980 steel sheets were used, which is the typical thickness for automotive applications. The DP980 sheets were $150 \mathrm{~mm}$ wide and $125 \mathrm{~mm}$ long.

Welding parameters for each wire were optimized based on visual inspection of bead morphology. The final set of welding parameters are tabulated in Tables 2 and 3, respectively. Figures 1 and 2 demonstrate the optimized BOP welds and cross sections of lap joints. Both the BOP welds and lap joints used $85 \% \mathrm{Ar}-15 \% \mathrm{CO}_{2}$ shielding gas. For all BOP welding, the welding torch had a 15-deg travel angle, and the weld length was $254 \mathrm{~mm}$. Lap joints $50 \mathrm{~mm}$ long were made in the middle of the 150-mm-long edge using both wires. The welding torch had a 15- to 17-deg travel angle and a 33-deg work angle.

\section{Distortion Measurement, Residual Stress Measurement, and Hardness Testing}

Distortion profiles of the welded plates were measured by a dial gauge. The plates were marked with $10 \times 10 \mathrm{~mm}$ square grids and fixed to a flat surface using wax. The distortion was measured with a dial gauge at every grid location. The resolution of distortion measurement was approximately $0.013 \mathrm{~mm}$ (0.0005 in.).

Neutron diffraction measurements were conducted at the $2^{\text {nd }}$ generation Neutron Residual Stress facility beam line of the High Flux Isotope Reactor (HFIR) at Oak Ridge National Laboratory (ORNL) (Ref. 5). Neutron diffraction mapping

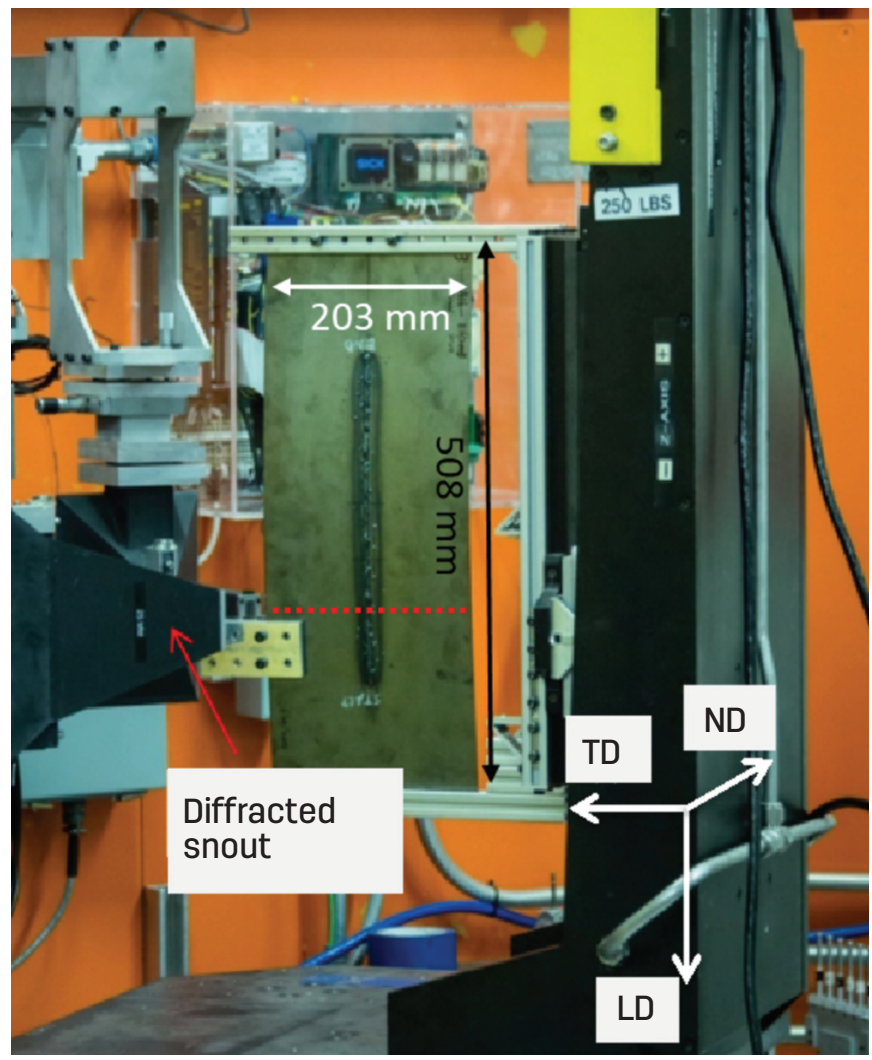

Fig. 3 - A neutron diffraction experiment setup at the $H B-2 B$ beam line of HFIR, ORNL. LD, TD, and ND denote longitudinal, transverse, and normal directions.

was performed along the transverse and longitudinal directions (TD and LD) to map the distribution lattice spacing, 


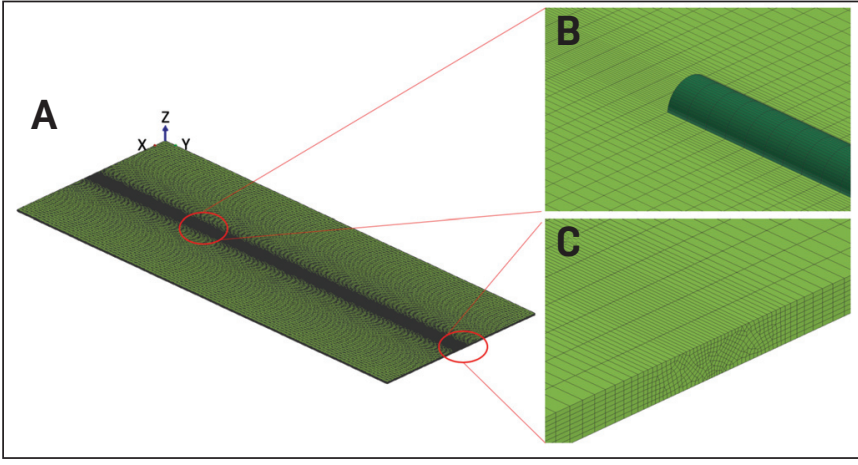

Fig. 4-A - The meshed model for the BOP weld; B, Cenlarged views showing the local meshes.

$\mathrm{d}_{211}$, in the welded plates. In the case of such a thin plate, the normal direction (ND) stress was assumed to be zero, and a plane stress assumption was utilized. The weld reference samples for $\mathrm{d}_{0,211}$ mapping were extracted from the welded plates using electric discharge machining to allow for mechanical relief of the residual stress while maintaining the chemical gradients across the HAZ and weld zone. The $\mathrm{d}_{0}$ samples were $2 \mathrm{~mm}$ thick along the LD, $12 \mathrm{~mm}$ long starting from the weld center toward the base metal along the TD; these plates had the same thickness as the welded plate. The stresses were calculated with 1) plane stress assumption, 2) elastic modulus $\mathrm{E}_{211}=220 \mathrm{GPa}$, and 3) Poisson's ratio $\mathrm{v}_{211}=$ 0.28 (Ref. 26). The neutron experimental setup is shown in Fig. 3 with the red dotted line across the weld representing the strain mapping locations. The beam slit size was about $0.5(\mathrm{ND}) \times 0.5(\mathrm{TD}) \times 10 \mathrm{~mm}(\mathrm{LD})$ for $\mathrm{TD}$ strain measurements and $0.5(\mathrm{ND}) \times 0.5$ (TD) $\times 0.5 \mathrm{~mm}(\mathrm{LD})$ for LD strain mapping. A relatively large vertical slit size was selected to reduce the measurement time at each mapping location in the TD measurements. All the mapping locations were located along the center thickness of the plate. The measurement time at each location was about 8 to 12 min for TD and up to $20 \mathrm{~min}$ for LD due to the decreased gauge volume.

\section{Metallographic Characterization}

Microstructural characterizations were performed using light optical microscopy (LOM), scanning electron microscopy (SEM), energy dispersive spectroscopy (EDS), $\mathrm{XRD}$, and electron backscattered diffraction (EBSD).

Samples for LOM analysis were cut at the weld-cross sections from the steady-state region of the welds. The samples were ground with 240-, 320-, 400-, 600-, 800-, and 1200-grit SiC abrasive papers, and then polished with 6, 3, and $1 \mu \mathrm{m}$ diamond suspensions. ER70S-3 and LTTW welds were etched by freshly prepared $2 \%$ nital and Kalling's No. 1 etchant, respectively. For SEM and EDS characterization, both the FEI Quanta 600i Environmental SEM and the JEOL JSM-7000F Field Emission SEM with Genesis EDS were used. To prepare samples for the SEM work, the same procedure as for LOM samples was used but with an extra 30-min vibratory polishing using $0.02 \mu \mathrm{m}$ noncrystallizing colloidal silica suspension. The samples were rinsed immediately after the final polishing with $2 \%$ micro organic soap (Allied 148-10000) to remove the remaining silica colloidal on the sample surface. EBSD samples were prepared the same way as the SEM samples. Images with a $50 \times 50 \mu \mathrm{m}$ area size under $2000 \times$ magnification were taken at the top, middle, and bottom of the weld transverse cross section, respectively, with a step size of $0.13 \mu \mathrm{m}$. The accelerated voltage was set to be $20 \mathrm{kV}$ with a $12-\mathrm{pA}$ probe current and a work distance of $18 \mathrm{~mm}$. The XRD sample was extracted by grinding off the reinforcement of the weld to maximize the area of examination, which was $15 \mathrm{~mm}$ (LD) $\times 5 \mathrm{~mm}$ (TD). $\mathrm{Cu}$ target was used with $45 \mathrm{kV}$ and $40 \mathrm{~mA}$; each test measurement lasted for $25 \mathrm{~min}$. The samples were first ground, polished, and cleaned in the freshly prepared solution (two parts hydrogen fluoride, 20 parts $\mathrm{H}_{2} \mathrm{O}_{2}, 20$ parts deionized water in volume ratio) for $15 \mathrm{~min}$ to remove the surface layer of scale and martensite phase that could potentially be induced by the mechanical force during the sample preparation process. X-ray diffraction results were analyzed based on the peak intensity of austenite $(\gamma)$ and martensite $\left(\alpha / \alpha^{\prime}\right)$ phases. The volume fraction of the $\gamma$ phase is calculated by averaging the ASTM standard (Ref. 27) as well as the literature by Deshayes (Ref. 28) and Cullity (Ref. 29), in which the volume fraction of $\gamma$ phase, $V \gamma$, can be calculated from the peak intensity, $I$, and the $\theta$-angle dependent function, $R$. Detailed expressions for these standards can be found in Refs. 27-29. Vickers hardness mapping was also performed on the welds. The testing loads were $500 \mathrm{~g}$ with a dwell time of $10 \mathrm{~s}$.

\section{Simulation Model}

The finite element (FE) code SYSWELD was used to calculate the complete residual stress profiles of the BOP welds using the two different consumables to quantify the effect of Ms and thus potentially optimize the residual stress control in the future through fine tuning of LTTW composition. The simulation constitutes two runs: a heat transfer analysis and a subsequent stress analysis. In the heat transfer model, the heat source parameters were adjusted based upon the experimentally observed weld fusion zone geometry. The residual stress calculation couples the thermal-mechanical-metallurgical effect involved in the welding process. In other words, the residual stress was determined by the temperature output and the physical properties of the phases, among which the most important factor was the martensitic transformation temperature. Detailed information about the model is given below. The calculated distortion and residual stresses were compared to the experimental results for validation purpose.

\section{Meshed Model}

The meshed model for the BOP weld was built based on the actual dimensions of the welded plates and the fusion zone morphology, as shown in Fig. 4 . The vicinity of the weld joint contains fine meshes to capture the thermomechanical behavior within and across different zones of interest under large temperature gradients and fluctuations imposed by the weld heat source. Coarser meshes were applied in the region away from the heat source boundary to reduce computation time without sacrificing accuracy. The models contained around 310,000 eight-node brick elements. 

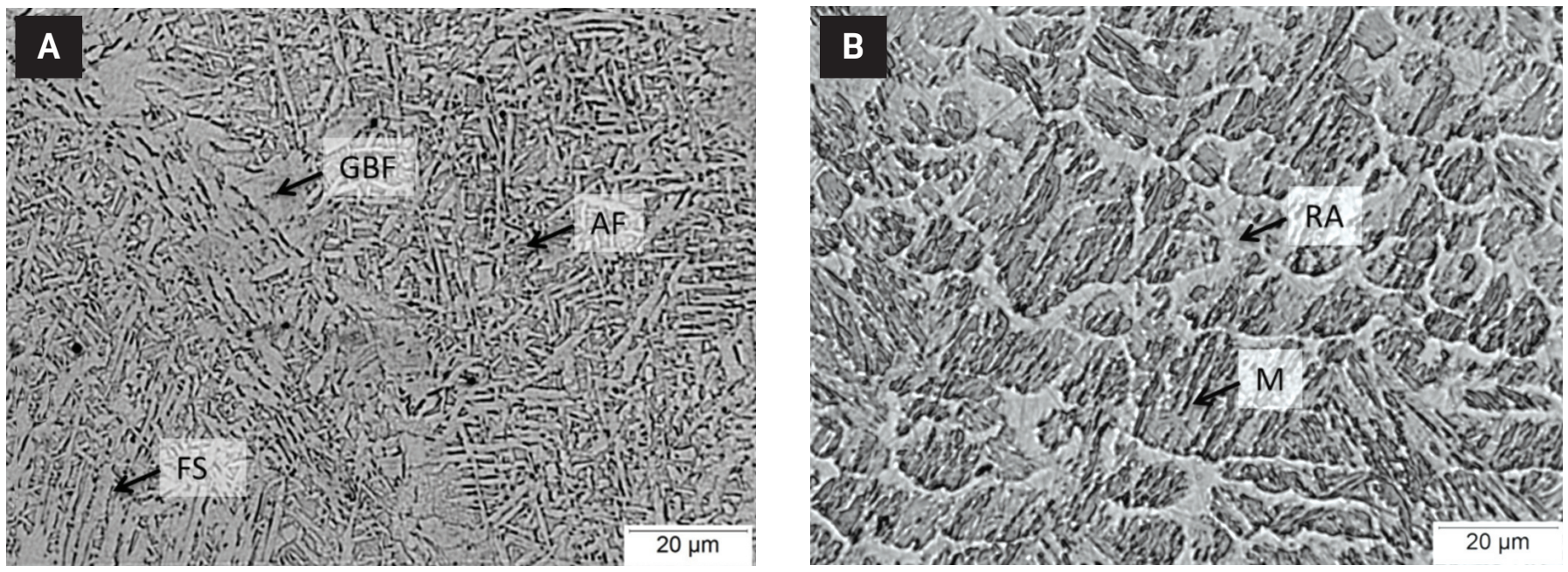

Fig. 5 - Weld microstructure by LOM using (A) ER7OS-3 and (B) EH2OOB wires. 2\% nital and Kalling's No. 1 etchant was used.

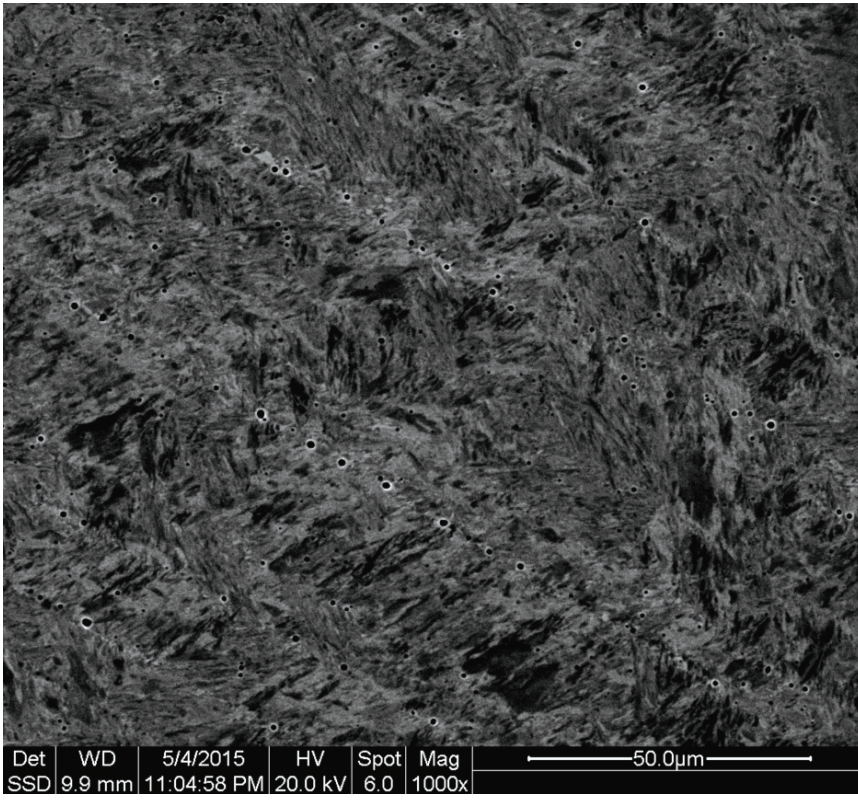

Fig. 6 - A backscattered electron image of the EH2OOB weld sample unetched.

\section{Material Database and Heat Source}

The temperature-dependent material properties for both the base and filler materials, including Young's modulus, specific heat, thermal conductivity, yield strength, density, and Poisson's ratio, were taken from Ref. 30. The Ms value used in SYSWELD was estimated using the Eichelman and Hull equation, as shown in Table 1 . The density value for EH200B was chosen as 7850 and $7290 \mathrm{~kg} / \mathrm{m}^{3}$ at $20^{\circ}$ and $1400^{\circ} \mathrm{C}$, respectively. The Poisson's ratio was set as 0.29 for the weld metal and 0.26 for the base metal. The latent heat of fusion was not considered in the simulations.

Goldak's three-dimensional double-ellipsoid model (Ref. 31) was used to input the volume heat source into the material. The dimensions of the double ellipsoid were adjusted to match the molten zone geometry from the experimental characterization. Gaussian distribution of the heat input was used in the Goldak heat source model. The total heat input energy was set based on the heat input value in Table 2. Surface convective and radiative loss was taken into consideration. The four corners of the plate were fixed as a mechanical boundary condition to represent the clamping condition in welding experiments.

\section{Results and Discussions}

\section{Microstructure in the BOP Welds}

As shown in Fig. 5A, grain boundary ferrite, ferrite with second phase, and acicular ferrite were present in the microstructure at the top weld region using ER70S-3 wire. For the weld produced using the EH200B wire, in Fig. 5B, the microstructure at the top region of the weld constitutes a large fraction of martensite (M) and retained austenite (RA). The presence of martensite in the EH200B weld was also demonstrated by backscattered electron image, as shown in Fig. 6 .

XRD and EBSD methods were used to quantify the fraction of martensite and RA phases. EBSD scanning results are shown in Fig. 7, in which the red color represents the martensite phase and the green color represents the retained austenite phase. The fraction of RA varied from $13 \%$ at the weld top, $9 \%$ in the middle, to $7 \%$ at the bottom; the remaining larger fraction in red was the martensite phase. The variation in the volume fraction of RA could be attributed to the differences in cooling rate from the weld top to the weld bottom. The bottom of the weld had a higher cooling rate than the weld top due to the surrounding base metal. Thus, the alloying elements had less time to segregate to the solidification cell boundaries, leading to less austenite to be stabilized and retained. The effect of elements segregation on the austenite stabilization can also be explained through the Schaeffler Diagram (Ref. 24). Moreover, the spacing between the retained austenite grains is around 20 $\mu \mathrm{m}$, which is close to the solidification cell width. Therefore, it is reasonable to conclude that RA followed the solidification boundary, to which all elements except iron segregated. Figure 8 shows the XRD pattern of the EH200B weld, demonstrating a much higher peak intensity from the 

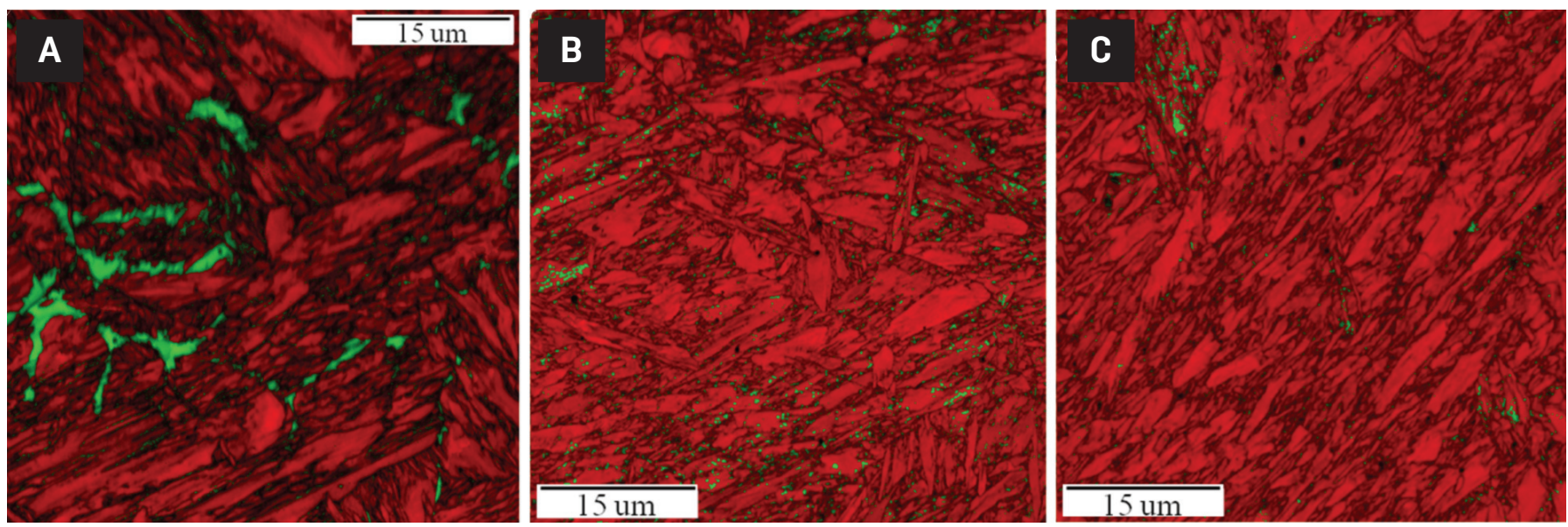

Fig. 7-EBSD results from the (A) top, (B) middle, (C) bottom locations of the EH200B weld transverse cross section. The red and green colors represent the martensite and austenite phases.

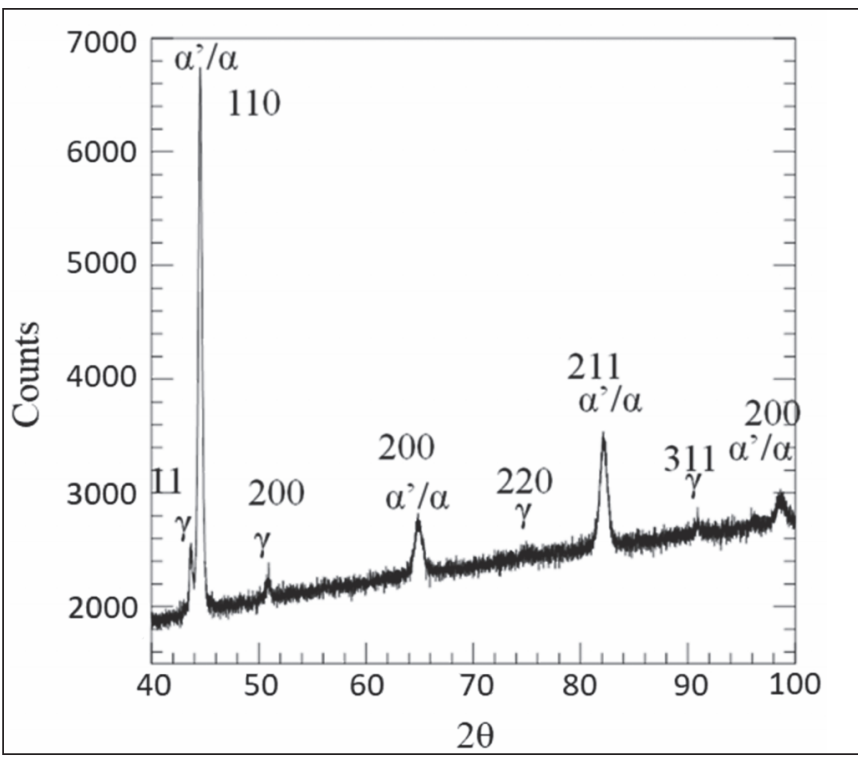

Fig. 8 - XRD data for the weld using EH2OOB wire.

Table 4 - Summary of Martensite Volume Fraction of EH200B Weld Using Both XRD and EBSD Techniques

\begin{tabular}{ccc} 
Technique & Austenite Fraction & Martensite Fraction \\
\hline XRD & $10.5 \%$ & $89.5 \%$ \\
EBSD & $9.6 \%$ & $90.3 \%$
\end{tabular}

martensite phase than that from RA. By averaging the calculated results from Cullity and Deshayes, as well as the ASTM standard, the austenite fraction in the EH200B weld was estimated to be about $10.5 \%$. The martensite volume fractions of EH200B weld predicted by both XRD and EBSD techniques are summarized in Table 4. It was reported that an appreciable amount of retained austenite could help prevent cold cracking (Ref. 32), and the amount of retained austenite can be controlled by adjusting the martensite starting temperature, $\mathrm{M}_{\mathrm{s}}$, and finishing temperature, $\mathrm{M}_{\mathrm{f}}$.

\section{Distortion in the BOP-Welded Plates}

The surface contours and profiles of the BOP weld sheets obtained from experimental measurement and FE analysis using EH200B and ER70S-3 wires are summarized in Fig. 9. Comparing Fig. 9A to $C$, it is obvious the two plates exhibited opposite distortion patterns. Along the LD, the welded plate using ER70S-3 wire had a concave shape while the welded plate using EH200B wire had a convex shape, which is an indication that the stress distributions in the two plates were possibly opposite. Similarly, opposite distortion patterns were observed along the TD, i.e., convex in ER70S3 and concave in EH200B. The simulation results showed reasonable agreement with the experimental measurements. From the distortion profiles shown in Fig. 9E and F, the opposite distortion patterns could also be clearly observed along the LD and TD.

\section{Residual Stresses in the BOP-Welded Plates}

Based on the line mapping of $\mathrm{d}$ and $\mathrm{d}_{0}$ spacing along the red dotted line in Fig. 3 along the TD and LD, residual strains $\varepsilon$ were calculated by $\left(\mathrm{d}-\mathrm{d}_{0}\right) / \mathrm{d}_{0}$, and the results are shown in Fig. 10. The bead width is close to $4 \mathrm{~mm}$ for both welds. As shown in Fig. 10A, EH200B led to a much lower LD strain in the weld region and the HAZ immediately adjacent to the weld than ER70S-3, which is expected for LTTW wire (Refs. 33-35). In comparison, a relatively high strain along the TD was observed in the EH200B weld as shown in Fig. 10B.

Figure 11 demonstrates the calculated LD residual stresses using Hooke's Law with plane stress assumption in the EH200B and ER70S-3 welds. Note that the stress curves were force balanced since a plane stress assumption within a very thin plate (i.e., $2 \mathrm{~mm}$ thick) indicates no significant change of stress along the thickness direction in the overall large welding plate of $508 \mathrm{~mm}$ long and $203 \mathrm{~mm}$ wide, although within the small weld bead and HAZ region (about 3-4 $\mathrm{mm}$ wide) stress variation along the thickness is expected. This assumption is supported by the simulation results. After stress balance within the whole plate, the maximum stress was reduced by $10 \%$ in the ER70S- 3 weld and $15 \%$ in 


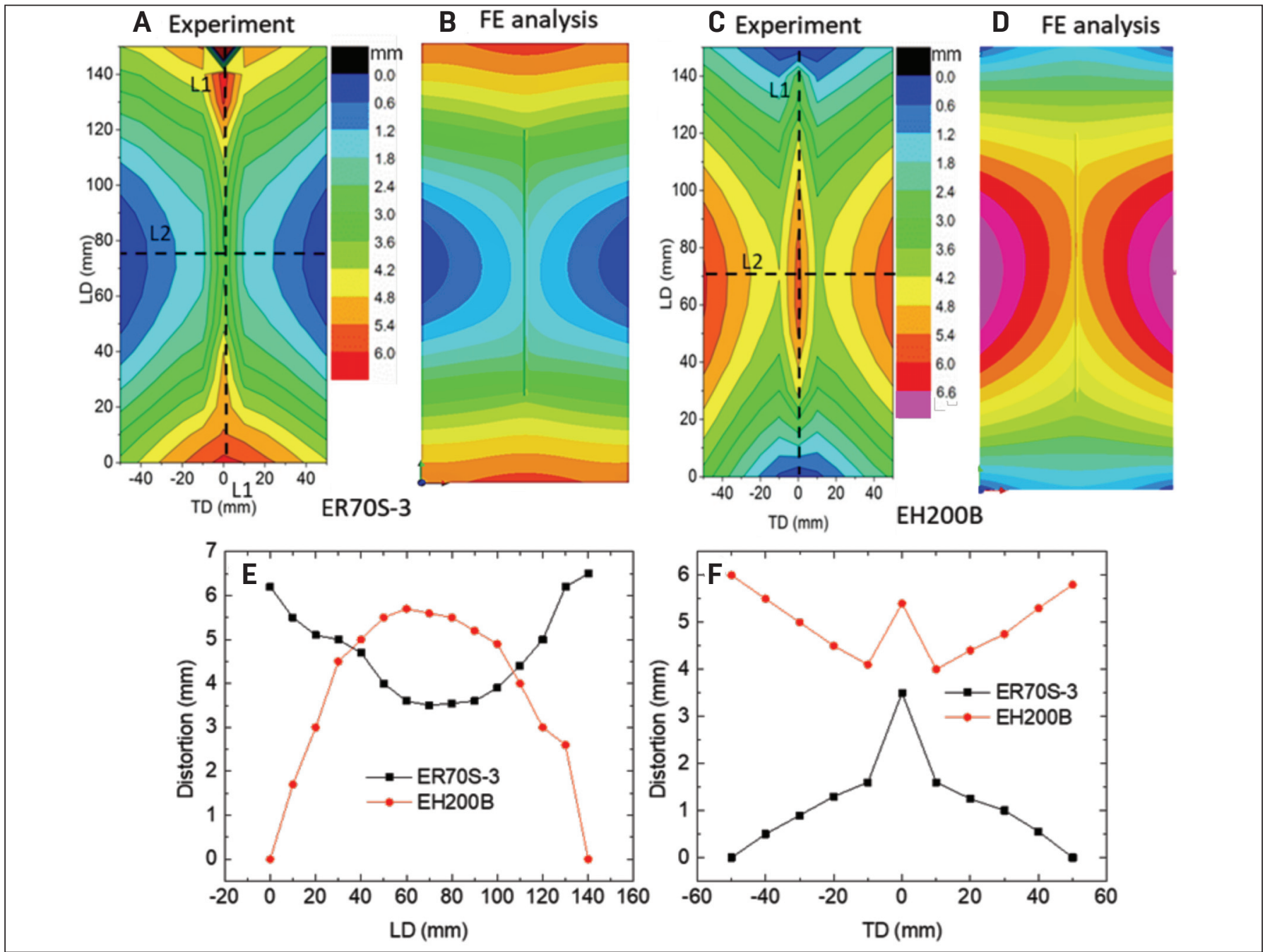

Fig. 9-A-D - Comparison of distortion contour maps obtained from experimental measurement and FE analysis in BOP welds using ER7OS-3 and EH200B; E, F - the corresponding distortion profiles from experimental measurement along the LD path LI and TD path L2 for ER7OS-3 and EH200B. Paths L1 and L2 are shown as dotted lines in $A$ and C.
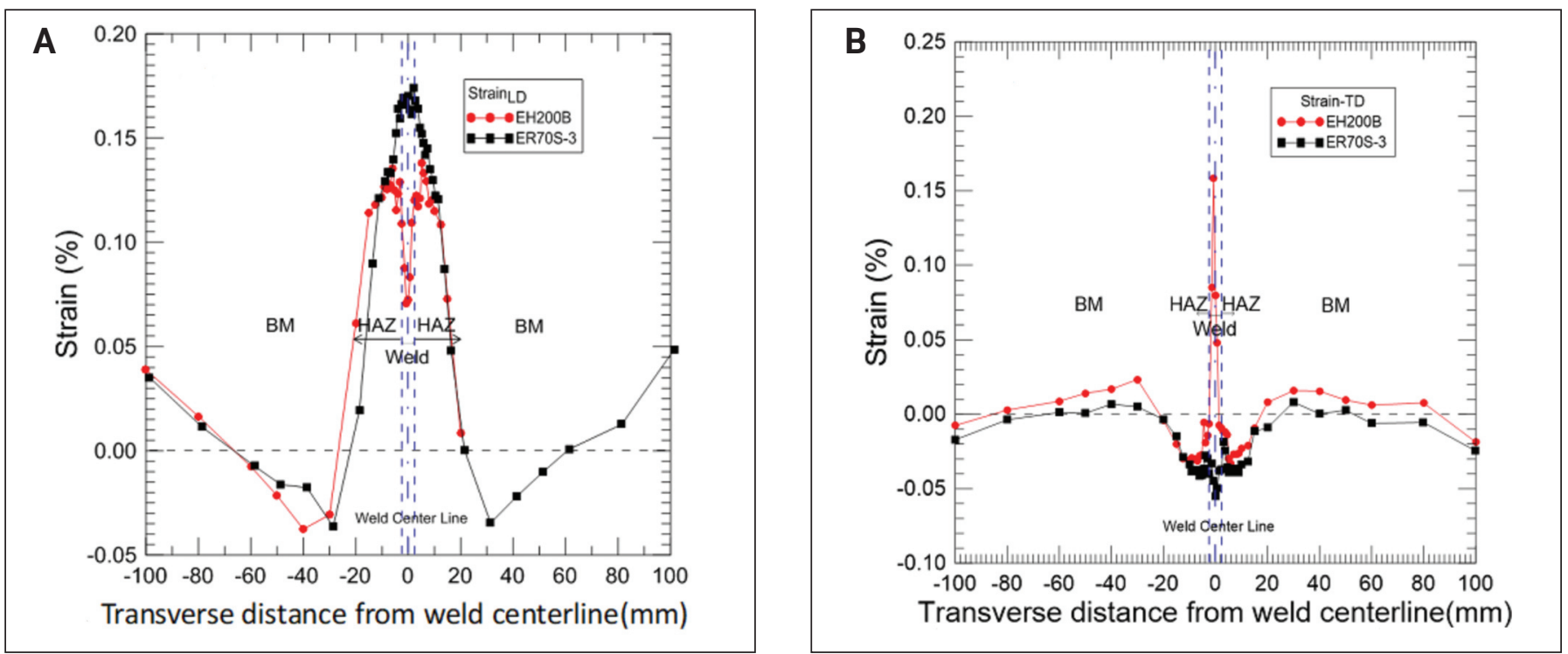

Fig. 10 - Strain distributions in (A) longitudinal and (B) transverse directions (LD and TD) in the welds using EH200B and ER70S-3. 


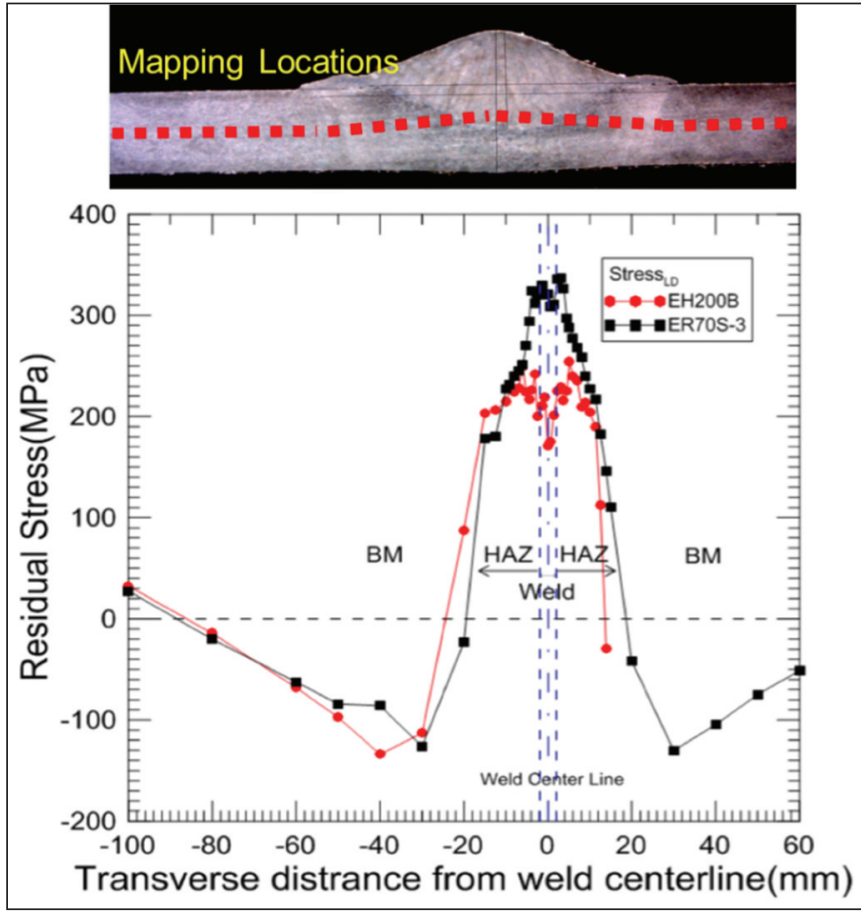

Fig. $11-L D$ residual stress measured by the neutron diffraction method with the mapping locations marked in the photograph above.

the EH200B weld. A potential cause of the data difference could be that the stresses in the reference samples were not completely relieved. Furthermore, the samples were allowed to deform after welding, meaning that some of the residual stress generated through welding, which would be maintained in a constrained sample, is relieved due to the deformation of the thin walled plates. The EH200B wire demonstrated to be effective in controlling residual stress in the HAZ but not the expected compressive residual stresses based on the opposite distortion pattern between the EH200B and ER70S-3 welds (Refs. 33-35). It is worth noticing that the large slit size used for the neutron diffraction measurement yields volume-averaged residual stress data, and due to the thin nature of the plates, a map through thickness is not feasible.

Finite element analysis provided a complete residual stress distribution, which is used to explain the stress profile obtained by the neutron diffraction experiment. Figure 12 gives the overall LD residual stress distributions predicted by SYSWELD for both LTTW and conventional wires. It was observed that, while the conventional wire induced large tensile stress in the weld zone, the LTTW wire would induce compressive residual stress in the weld. Despite the material database used for EH200B from literature (Ref. 30) possibly leading to some deviations from the experimental measurement results, it should not cause the large deviation as observed between Figs. 11 and 12. The main reason for the observed discrepancy can be attributed to the relatively large sampling area, i.e., $0.7 \times 0.7 \mathrm{~mm}$, in comparison to the 2-mm plate thickness and 4-mm bead width, as indicated in Fig. 13B, C. Therefore, the stress profile in Fig. 13A that averaged the values of the sampling area matches the neutron diffraction results reasonably well, which covers both tensile

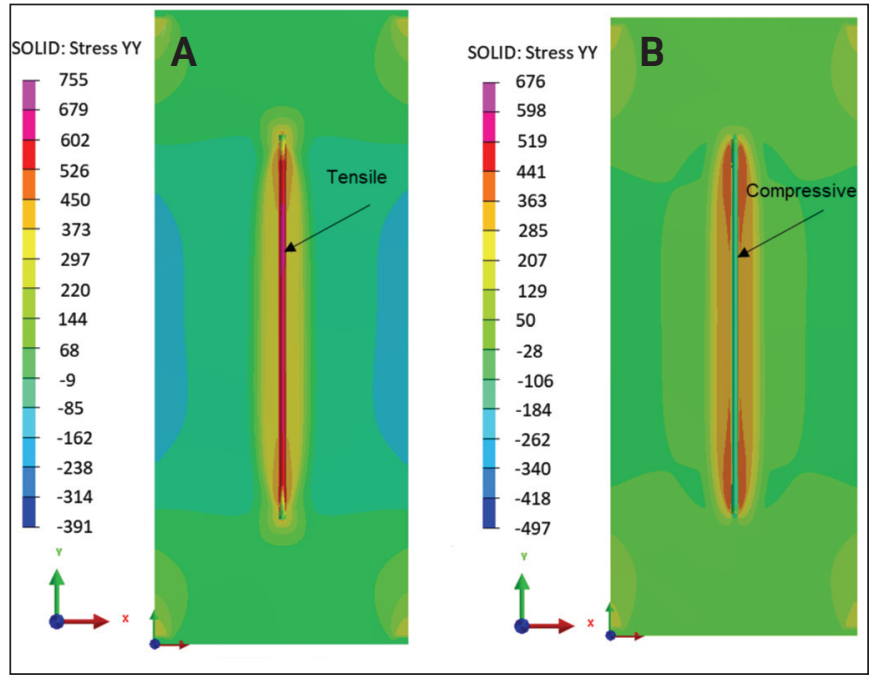

Fig. 12 - Overall residual stress contour distributions along LD for BOP welded by (A) ER70S-3 and (B) EH200B.
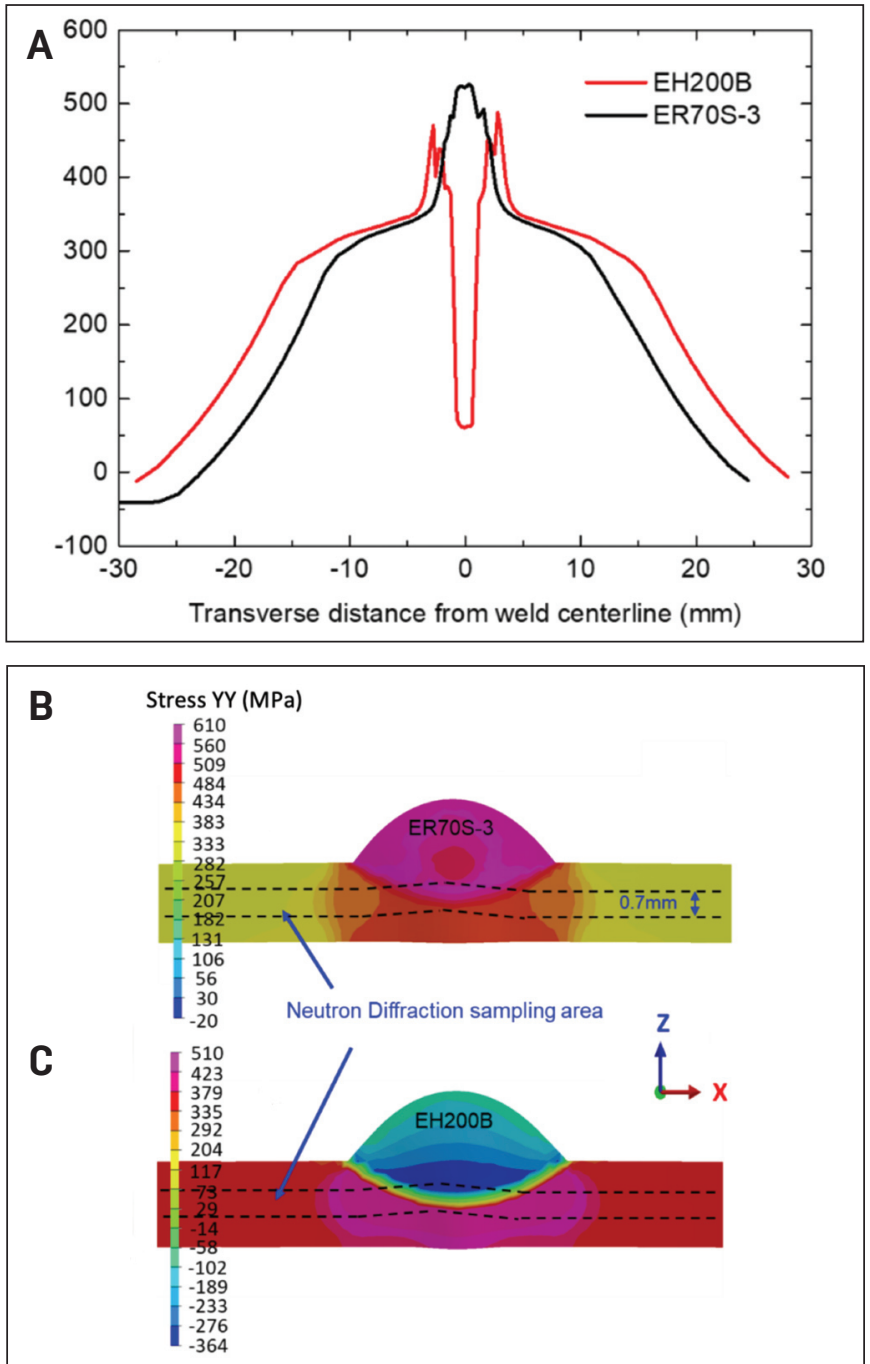

Fig. $13-A-L D$ residual stress profiles averaged in the sampling areas marked in $(B)$ and $(C)$ cross-sectional stress contour predicted by FE analysis in ER70S-3 and EH2OOB welds. 

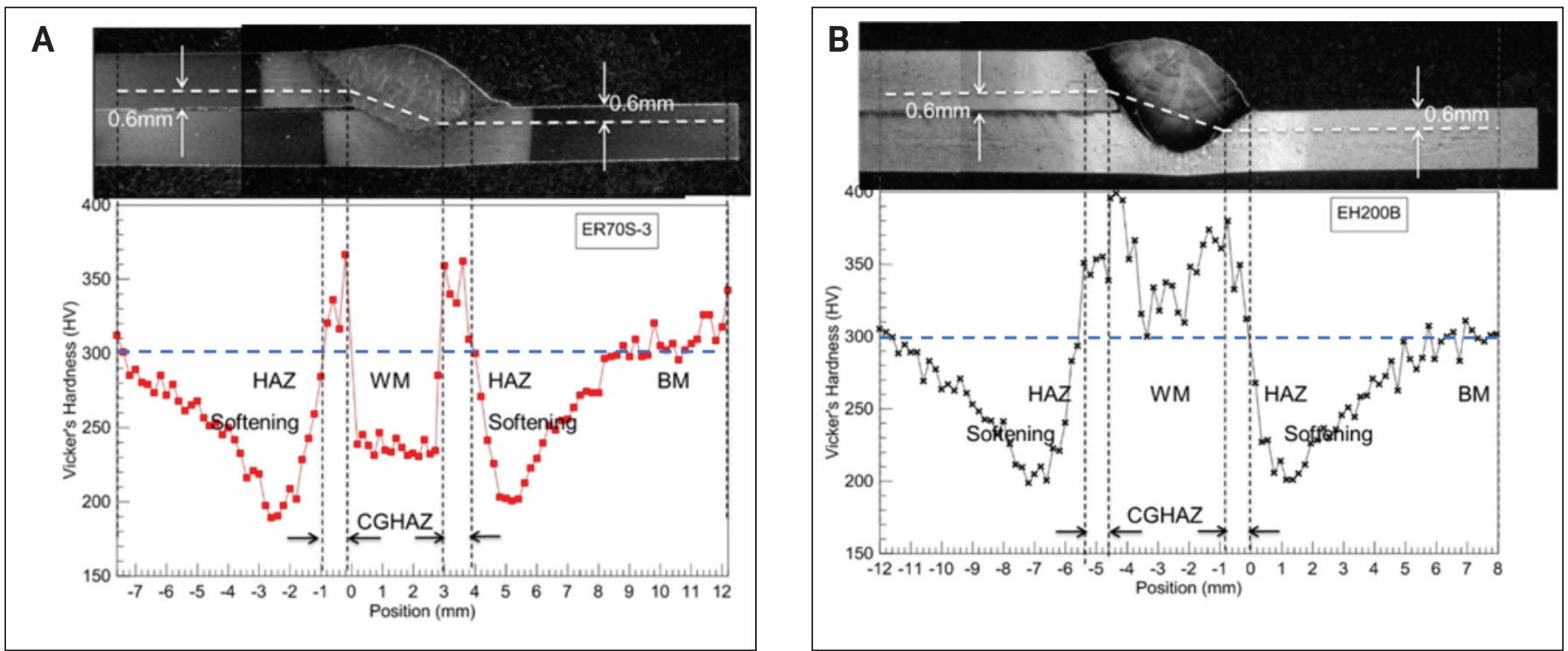

Fig. 14 - Optical macrographs of the weld transverse cross sections using (A) ER70S-3 and (B) EH200B wires, respectively, and their Vickers hardness line mapping results.

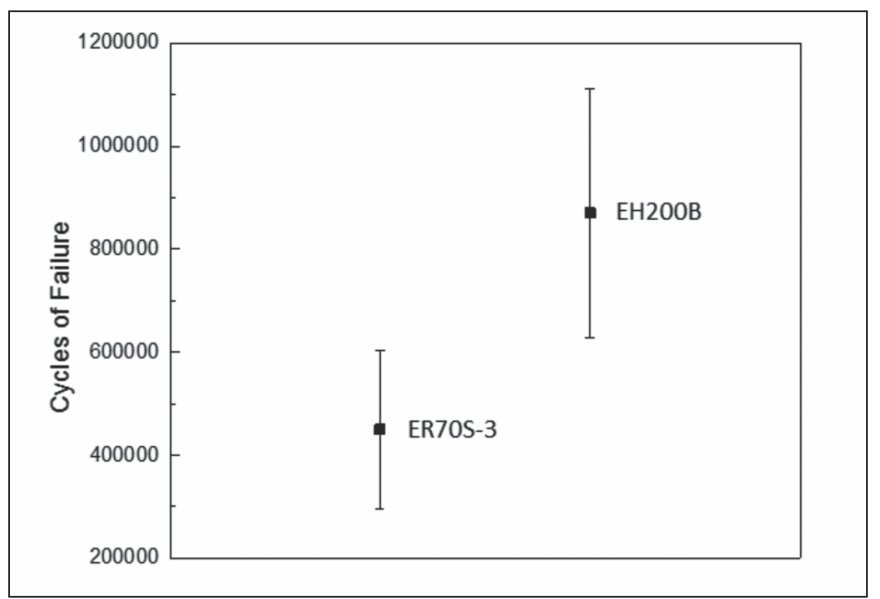

Fig. 15 - Fatigue life comparison of the welds made by ER70S-3 and EH2OOB.

and compressive stress regions. Moreover, the opposite stress profiles in Fig. 12 are in agreement with the opposite distortion patterns in Fig. 9 between the two welds. For better distortion control in the future, the LTTW wire composition (i.e., Ms) may need to be further optimized to lower the martensite fraction and thus reduce the tensile residual stress to near zero instead of compressive.

\section{Microhardness and Fatigue Life of Lap Joints}

Vickers hardness line mapping results across the DP980 lap joints made with both wires are summarized in Fig. 14. The DP980 steel base metal shows an average hardness of 300 HV. The HAZ softening was observed in both welds since the materials in the HAZ experienced similar thermal profiles. A dashed horizontal line at $300 \mathrm{HV}$ was drawn in Fig. 14 to demonstrate the undermatching and overmatching phenomenon in the weld metals generated from ER70S-3 and EH200B wires, respectively. EH200B wire was overmatching due to the presence of more than $87 \%$ of the martensite phase, while the ER70S-3 wire was undermatching because of the prevalent ferrite phase. For the EH200B weld, the hardness varied between 300 to $400 \mathrm{HV}$. In comparison, the hardness for the ER70S- 3 weld was as low as 230 to $250 \mathrm{HV}$. The coarse grain HAZ with a coarse martensite microstructure was present right next to the ER70S-3 weld interface, leading to an increase in hardness up to 370 $\mathrm{HV}$.

A fatigue test was also conducted on lap joints produced by these two wires with a maximum load level of $9.5 \mathrm{kN}$ (i.e., a maximum stress level of $95 \mathrm{MPa}$ ), a stress ratio of a minimum to maximum of 0.1 at a frequency of $10 \mathrm{~Hz}$. Three lap joint welds of each wire were tested. The average fatigue life of lap joint panels using the $\mathrm{EH} 200 \mathrm{~B}$ wire was about $8.7 \times 10^{5}$ cycles in comparison to the $4.5 \times 10^{5}$ cycles using the ER70S- 3 wire, as shown in Fig. 15. Therefore, EH200B nearly doubled the fatigue life of the DP980 thin sheet lap joints, which is most likely caused by a combination of increased strength in the fusion zone and lower residual stress in the HAZ.

\section{Conclusion}

1) The newly developed LTTW consumable, EH200B wire, effectively lowered the LD residual stresses in the fusion zone and HAZ in comparison to the conventional ER70S-3 wire in the BOP welds of thin steel sheets.

2) Microstructural characterization of the weld metal showed that more than $87 \%$ of martensite was generated in the weld using EH200B wire.

3) A FE numerical model was developed to simulate the stress and distortion initiated for the weld under two different types of wires. The simulation results obtained similar distortion patterns for the two wires. Meanwhile, the stress distribution profile in the neutron diffraction test was explained, and a compressive residual stress in the weld for LTTW was predicted. 
4) With a high fraction of martensite ( 90\%), the EH200B wire generated an opposite distortion pattern in the BOP weld to ER70S-3 wire. For a better distortion control, the LTTW wire composition may need to be further optimized to lower the martensite fraction and reduce the tensile residual stress to near zero instead of compressive.

5) Fatigue life of DP980 lap joint panels using the EH200B wire nearly doubled that of the ER70S-3 wire because of the high strength of the weld and lower LD residual stress in the HAZ and weld regions.

\section{Acknowledgments}

This research was financially sponsored by the U.S. Department of Energy (DOE) Assistant Secretary for Energy Efficiency and Renewable Energy, Office of Vehicle Technologies, as part of the Lightweight Materials Program, through a subcontract from Oak Ridge National Laboratory (ORNL). ORNL is managed by UT-Battelle LLC for the U.S. Department of Energy under Contract DE-AC05-

00OR22725. This research used resources at the High Flux Isotope Reactor, a DOE Office of Science User Facility operated by the ORNL. The authors acknowledge the National Science Foundation, Industry and University Cooperative Research Center, and The Manufacturing and Materials Joining Innovation Center for the opportunity to conduct this research, as well as Devasco International for providing the experimental wires and supplementary funding. The authors would also like to gratefully acknowledge ESI Group for making the SYSWELD software available to the researchers of the Center for Welding, Joining and Coatings Research of the Colorado School of Mines. Their technical support and discussion are also kindly appreciated. The authors also acknowledge T. Alghamdi and Sindhu Thomas for their prior work related to the development of the EH200B alloy.

\section{References}

1. Kapustka, N., Conrardy, C., Babu, S., and Albright, C. 2008. Effect of GMAW process and material conditions on DP 780 and TRIP 780 welds. Welding Journal 87(6): 135-s to 148-s.

2. Lambert, A., Drillet, J., Gourgues, A. F., Sturel, T., and Pineau, A. 2000. Microstructure of martensite-austenite constituents in heat affected zones of high strength low alloy steel welds in relation to toughness properties. Science and Technology of Welding and Joining 5: 168-173. DOI: 10.1179/ 136217100101538164

3. Ceglarek, D., Shi, J., and Wu, S. M. 1994. A knowledge-based diagnostic approach for the launch of the auto-body assembly proces. Journal of Engineering for Industry 116: 491-499. DOI: 10.1115/1.2902133

4. Zhu, W., Xu, C., and Zeng, L. 2010. Coupled finite element analysis of MIG welding assembly on auto-body high-strength steel panel and door hinge. International Journal of Advanced Manufacturing Technology 51: 551-559. DOI: 10.1007/s00170-010-2646-y

5. Kurkin, S. A., and Anufriev, V. I. 1984. Preventing distortion of welded thin-walled members of AMg6 1201 Aluminum alloys by rolling the weld with a roller behind the welding arc. Welding Production (English translation of Svarochnoe Proizvodstvo) 31: 52-55.

6. Kurkin, S. A., Anufriev, V. I., and Milekhin, E. S. 1980. Im- proving the mechanical properties of welded joints in the AMg6 alloy by plastic deformation during arc welding. Svarochnoe Proizvodstvo 27: 20-24.

7. Liu, W., Tian, X., and Zhang, X. 1996. Preventing weld hot cracking by synchronous rolling during welding. Welding Journal 75(9): 297-s to 304-s.

8. Jones, W. K. C., and Alberry, P. J. 1977. A Model for stress accumulation in steels during welding, residual stresses in welded construction and their effects. The Welding Institute: pp. 15-26.

9. Ohta, A., Suzuki, N., and Maeda, Y. 2000. Doubled fatigue strength of box welds by using low transformation temperature welding material. Properties of Complex Inorganic Solids 2: 401-408. Kluwer Academic/Plenum Publishers, New York.

DOI: 10.1007/978-1-4615-1205-9_29

10. Ohta, A., Watanabe, O., Matsuoka, K., Siga, C., Nishijima, S., Maeda, Y., Suzuki, N., and Kubo, T. 1999. Fatigue strength improvement by using newly developed low transformation temperature welding material. Welding in the World 43: 38-42.

11. Ohta, A., Suzuki, N., Maeda, Y., Hiraoka, K., and Nakamura, T. 1999. Superior fatigue crack growth properties in newly developed weld metal. International Journal of Fatigue 21: 113-118. DOI: 10.1016/S0142-1123(99)00062-6

12. Martinez Diez, F., and Liu S. 2007. Compositional boundary between primary austenitic and ferritic $\mathrm{Mn}-\mathrm{Cr}$ and $\mathrm{Ni}-\mathrm{Cr}$ steel weld metals. Materials Science and Engineering A (452-453): 1-7. DOI: 10.1016/j.msea.2006.11.108

13. Payares-Asprino, M. C., Katsumoto, H., and Liu, S. 2008. Effect of martensite start and finish temperature on residual stress development in structural steel welds. Welding Journal 87(11): 279-s to 289-s.

14. Alghamdi, T., and Liu, S. 2014. Low transformation temperature welding consumables for residual stress management: $\mathrm{A} \mathrm{nu}-$ merical model for the prediction of phase transformation-induced compressive residual stresses. Welding Journal 93(12): 458-s to 471-s.

15. Xu, L. Y., Wang, Y. F., Jing, H. Y., and Han, Y. D. 2014. Fatigue strength improvement of stainless steel using weld toes dressing with low transformation temperature welding wire. Science and Technology of Welding and Joining 19: 664-672. DOI: 10.1179/1362171814Y.0000000240

16. Thomas, S. H., and Liu, S. 2014. Analysis of low transformation temperature welding (LTTW) consumables - Distortion control and evolution of stresses. Science and Technology of Welding and Joining 19: 392-401. DOI: 10.1179/1362171814Y.0000000199

17. Darcis, P. H., Katsumoto, H., Payares-Asprino, M. C., Liu, S., and Siewert, T. A. 2008. Cruciform fillet welded joint fatigue strength improvements by weld metal phase transformations. Fatigue \& Fracture of Engineering Materials and Structures 31:

125-136. DOI: 10.1111/j.1460-2695.2007.01205.x

18. Wang, W. X., Huo, L. X., Zhang, Y. F., Wang, D. P., and Jing, H. Y. 2002. New developed welding electrode for improving the fatigue strength of welded joints. Journal of Materials Science and Technology 18: 527-531.

19. Ohta, A., Matsuoka, K., Nguyen, N. T., Maeda,Y., and Suzuki, N. 2003. Fatigue strength improvement of lap joints of thin steel plate using low-transformation-temperature welding wire. Welding Journal 82(4): 78-s to 83-s.

20. Camilleri, D., McPherson, N., and Gray, T. G. F. 2013. The applicability of using low transformation temperature welding wire to minimize unwanted residual stresses and distortions. International Journal of Pressure Vessels and Piping 110: 2-8. DOI: 10.1016/j.ijpvp.2013.04.014

21. Saraiva, D. L., Béreš, M., Silva, C. C., Nunes, C. S., Silva, J. J. M., and Abreu, H. F. G. 2014. Application of low $\mathrm{M}_{\mathrm{s}}$ temperature consumable to dissimilar welded joint. Materials Science and Technology 30: 1057-1062. DOI: 10.1179/1743284714Y.0000000516

22. Alghamdi, T., and Liu, S. 2014. Low-transformation-tem- 
perature (LTT) welding consumables for residual stress management: Consumables development and testing qualification. Welding Journal 93(12): 243-s to 252-s.

23. Eichelman, G. H., and Hull, F. 1953. The Effect of composition on the temperature of spontaneous transformation of austenite to martensite in 18-8 type stainless steel. Transactions of the American Society for Metals 45: 77-104.

24. Schaeffler, A. L. 1949. Constitution diagram for stainless steel weld metal. Metal Progress 56: 680-680B.

25. Cornwell, P., Bunn, J., Fancher, C. M., Payzant, E. A., and Hubbard, C. R. 2018. Current capabilities of the residual stress diffractometer at the high flux isotope reactor. Review of Scientific Instruments 89: 092804. DOI: 10.1063/1.5037593

26. Acevedo, C., Evans, A., and Nussbaumer, A. 2012. Neutron diffraction investigations on residual stresses contributing to the fatigue crack growth in ferritic steel tubular bridges. International Journal of Pressure Vessels and Piping 95: 31-38. DOI: 10.1016/ j.ijpvp.2012.05.004

27. ASTM International. ASTM E975-84, X-ray Determination of Retained Austenite in Steel with Near Random Crystallographic Orientation, pp. 787-794. West Conshohocken, Pa.: ASTM International

28. Deshayes, P. 1995. PhD thesis, L'Université des Sciences et Technologies de Lille.

29. Cullity, B. D. 1978. Elements of X-Ray Diffraction, $2^{\text {nd }}$ ed. Reading, Pa.: Addison-Wesley Publishing Co., p. 508.

30. Alghamdi, T., and Liu, S. 2014. Low transformation temperature welding consumables for residual stress management: A numerical model for the prediction of phase transformation induced compressive residual stresses. Welding Journal 93(12): 458-s to 471-s.

31. Goldak, J., Chakravarti, A., and Bibby, M. 1984. A new finite element model for welding heat sources. Metallurgical Transactions B 15: 299-305. DOI: 10.1007/BF02667333

32. Kromm, A., and Kannengiesser, T. 2011. Characterizing phase transformations of different LTT alloys and their effect on residual stresses and cold cracking. Welding in the World 55: 48-56. DOI: 10.1007/BF03321286

33. Chen, X., Fang, Y., Li, P., Yu, Z., Wu, X., and Li, D. 2015. Microstructure, residual stress and mechanical properties of a high strength steel weld using low transformation temperature welding wires. Materials and Design 65: 1214-1221. DOI: 10.1016/ j.matdes.2014.10.013

34. Dai, H., Francis, J. A., Stone, H. J., Bhadeshia, H. K. D. H., and Withers, P. J. 2008. Characterizing phase transformations and their effects on ferritic weld residual stresses with $\mathrm{x}$-rays and neutrons. Metallurgical and Materials Transactions A 39: 3070-3078. DOI: 10.1007/s11661-008-9616-0

35. Gadallah, R., Tsutsumi, S., Hiraoka, K., and Murakawa, H. 2015. Prediction of residual stresses induced by low transformation temperature weld wires and its validation using the contour method. Marine Structures 44: 232-253. DOI: 10.1016/ j.marstruc.2015.10.002

XIN WU (xinwu350@gmail.com), ZHIFEN WANG, ZHENZHEN $Y U$, and STEPHEN LIU are with the George S. Ansell Department of Metallurgical and Materials Engineering, Colorado School of Mines, Golden, Colo. JEFFREY R. BUNN, LINDSAY KOLBUS, and ZHILI FENG are with Oak Ridge National Laboratory, Oak Ridge, Tenn.

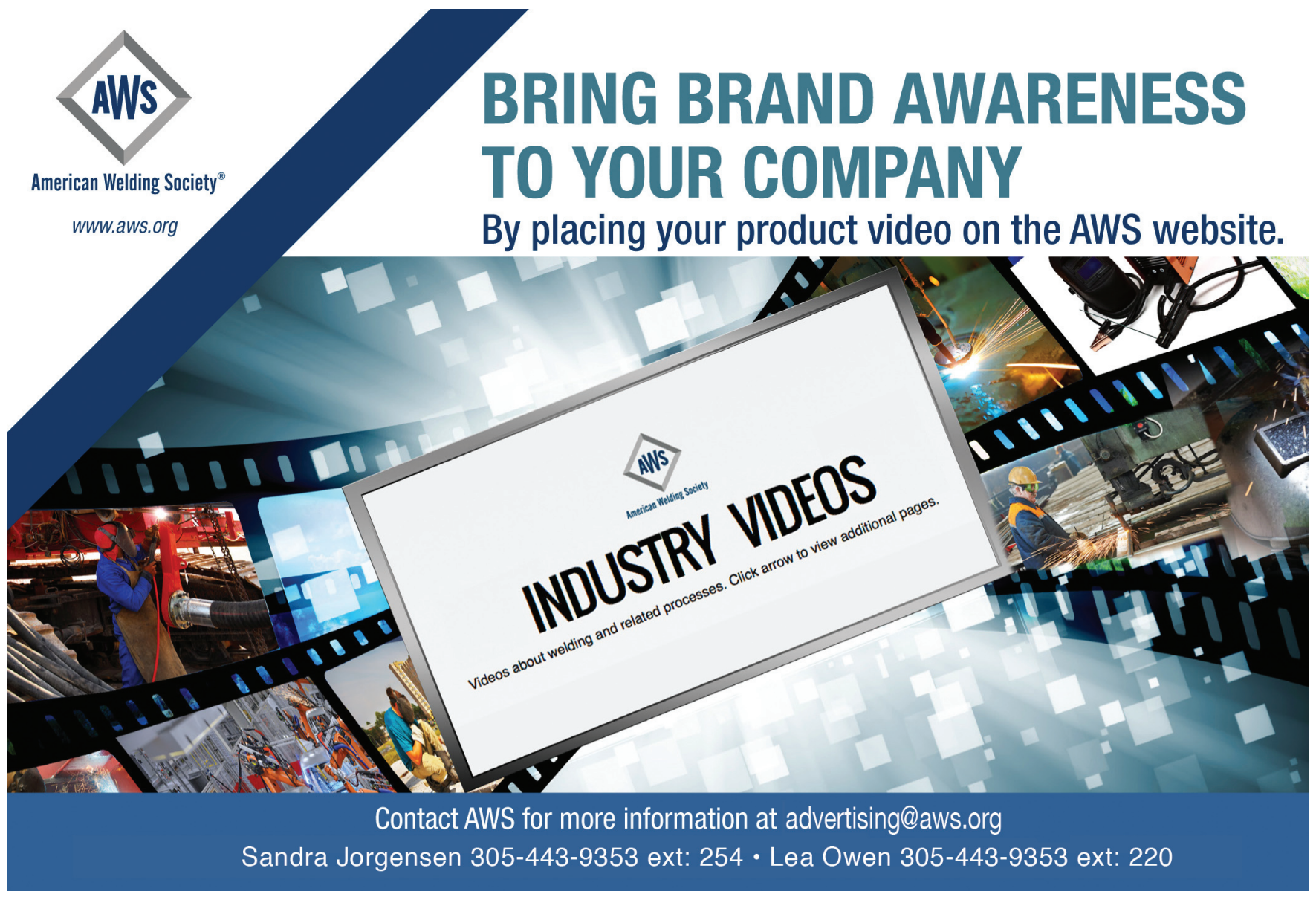

